\title{
Magnetic Shielding Study of Bonding and Aromaticity in Corannulene and Coronene
}

\author{
Peter B. Karadakov
}

Citation: Karadakov, P.B. Magnetic Shielding Study of Bonding and Aromaticity in Corannulene and Coronene. Chemistry 2021, 3, 861-872. https://doi.org/10.3390/ chemistry3030063

Academic Editors: Andrea Peluso and Guglielmo Monaco

Received: 1 August 2021

Accepted: 9 August 2021

Published: 12 August 2021

Publisher's Note: MDPI stays neutral with regard to jurisdictional claims in published maps and institutional affiliations.

Copyright: (C) 2021 by the author. Licensee MDPI, Basel, Switzerland. This article is an open access article distributed under the terms and conditions of the Creative Commons Attribution (CC BY) license (https:// creativecommons.org/licenses/by/ $4.0 /)$.
Department of Chemistry, University of York, Heslington, York YO10 5DD, UK; peter.karadakov@york.ac.uk

\begin{abstract}
Bonding and aromaticity in the bowl-shaped $C_{5 \mathrm{v}}$ and planar $D_{5 \mathrm{~h}}$ geometries of corannulene and the planar $D_{6 \mathrm{~h}}$ geometry of coronene are investigated using 3D isosurfaces and 2D contour plots of the isotropic magnetic shielding $\sigma_{\text {iso }}(\mathbf{r})$ and, for planar geometries, of the out-of-plane component of the shielding tensor $\sigma_{z z}(\mathbf{r})$. Corannulene and coronene both feature conjoined shielded "doughnuts" around a peripheral six-membered carbon ring, suggesting strong bonding interactions and aromatic stability; a deshielded region inside the hub ring of corannulene indicates that this ring is antiaromatic, more so in planar corannulene. The switch from the planar to the bowl-shaped geometry of corannulene is shown to enhance both bonding and the local aromaticities of the fiveand six-membered rings; these factors, in addition to ring strain reduction, favour the bowl-shaped geometry. The most and least shielded bonds in both corannulene and coronene turn out to be the spoke and hub bonds, respectively. The higher $\pi$ electron activity over spoke bonds in planar corannulene and coronene is supported by $\sigma_{z z}(\mathbf{r})$ contour plots in planes $1 \AA$ above the respective molecular planes; these findings about spoke bonds are somewhat unexpected, given that ring current studies indicate next to no currents over spoke bonds.
\end{abstract}

Keywords: aromaticity; antiaromaticity; corannulene; coronene; magnetic shielding isosurfaces; magnetic shielding contour plots; shielding over chemical bonds

\section{Introduction}

The polycyclic aromatic hydrocarbon (PAH) dibenzo[ghi,mno]fluoranthene $\left(\mathrm{C}_{20} \mathrm{H}_{10}\right)$, in which a five-membered central ring is surrounded by five six-membered rings, was synthesised by Barth and Lawton in 1966 [1], who gave it the trivial name under which it is currently known, corannulene (see also [2]). The discovery of buckminsterfullerene, $\mathrm{C}_{60}$, in 1985 [3], led to an "explosion" of interest in corannulene, as chemists quickly realised that it was the smallest subunit of the buckyball motif that retains a curved bowl-like shape of $C_{5 \mathrm{v}}$ symmetry. Corannulene is now widely utilised as a polyarene building block for the construction of functional materials [4], and its importance is emphasised by the availability of a process for the kilogram-scale production of this PAH [5].

Interest in the aromaticity of corannulene was one of the incentives for its initial synthesis: Barth and Lawton thought that ionic resonance structures such as that in Figure 1d could give rise to two charged concentric conjugated systems, an inner cyclopentadienyl anion and an outer cyclopentadecaheptenyl cation, each of which satisfies Hückel's $4 n+2$ rule. This "annulene-within-an-annulene" (AWA) model could also be expected to apply to planar coronene $\left(\mathrm{C}_{24} \mathrm{H}_{12}\right)$, which has inner and outer rings with $6 \pi$ and $14 \pi$ electrons, respectively. As explained by Zanasi and coworkers [6], the AWA model would work if the inner and outer annulene rings were uncoupled, which is an unrealistic assumption as the carbon-carbon spoke bonds connecting the two rings have been found to be shorter than the hub, flank and rim bonds (see Figure 1a for definitions). 


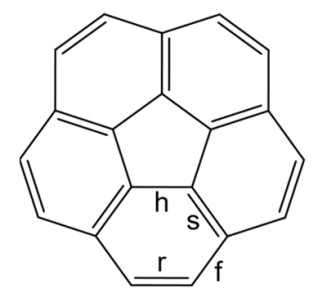

(a) $\mathrm{K}_{1}$

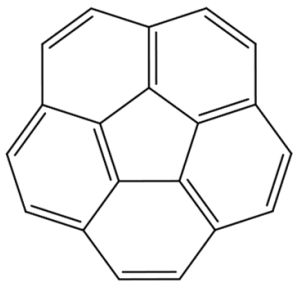

(b) $5 \times \mathrm{K}_{2}$

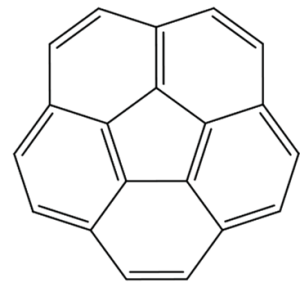

(c) $5 \times \mathrm{K}_{3}$

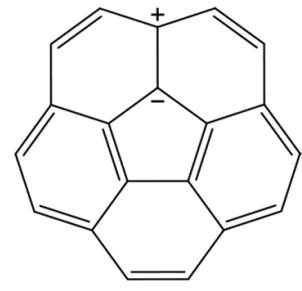

(d)

Figure 1. Kekulé $(\mathbf{a}-\mathbf{c})$ and one ionic resonance structure $(\mathbf{d})$ for corannulene. The positions of the carbon-carbon hub (h), spoke (s), flank (f) and rim (r) bonds are shown in (a). The carbon atoms are referred to as hub (involved in two hub bonds), flank (involved in two flank bonds) and rim.

Valence bond (VB) theory provides a simple argument against the AWA model [6]: Corannulene has 11 Kekule resonance structures (see Figure 1a-c), and each of the five spoke bonds is double in five of these resonance structures. At the moment, it is not possible to quantify the relative importance of the Kekule resonance structures of types $K_{1}, K_{2}$ and $\mathrm{K}_{3}$ using modern VB theory, because a spin-coupled generalised VB (SCGVB) [7] calculation with 20 active orbitals is still not computationally feasible (the overall number of unique covalent resonance structures for a 20-electron singlet is 16,796; these include, in addition to the 11 Kekulé resonance structures, a number of less important para-bonded structures, similar to the Dewar structures in benzene, and many other structures with longer pair separations). However, chemical intuition and SCGVB experience with naphthalene [8] suggest that the weight of $K_{1}$, which includes five $\pi$ sextets, will be higher than the combined weight of structures $K_{2}$, each of which includes three $\pi$ sextets, followed by the combined weight of structures $K_{3}$, each of which includes two $\pi$ sextets; this emphasizes the importance of the spoke bonds and lends additional support to the counter-AWA argument.

Interestingly, the population analysis results reported by Sygula and Rabideau [9], which have been quoted to "show no significant redistribution of electron density from rim to hub" in corannulene [10], include data about the corannulene dianions and tetraanion but not about neutral corannulene. Mulliken charges obtained in the current study show strong basis set dependence and produce contradictory results: the $6-311++\mathrm{G}(\mathrm{d}, \mathrm{p})$ charges suggest a substantial rim-to-hub charge shift, whereas the def2-TZVP charges suggest a minor hub-to-rim charge shift. Whereas other types of population analysis may show better consistency, the use of such methods in support for or against the AWA model is questionable.

Both corannulene and coronene have been found to feature counter-rotating ring currents, with a diamagnetic (aromatic) rim and a paramagnetic (antiaromatic) hub, in stark contrast with the predictions of the AWA model [10]. This is in line with NICS(0) results, according to which the inner ring in corannulene is antiaromatic and each of the outer rings is aromatic, the inner ring in coronene is weakly antiaromatic or nonaromatic and each of the outer rings is aromatic, more so than the outer rings in corannulene [10-12]. NICS(0) is the original nucleus-independent chemical shift suggested by Schleyer and coworkers [13], defined as the isotropic magnetic shielding evaluated at the centre of an aromatic or antiaromatic ring and taken with a reversed sign, $-\sigma_{\text {iso }}$ (at ring centre). Enlargements of corannulene and coronene, resulting in altan-corannulene and altan-coronene, have been shown to feature patterns of three contra-rotating paratropic/diatropic/paratropic circulations [14,15]; even more complicated ring current pictures have been reported for $(\text { altan })^{n}$-corannulene and (altan) $)^{n}$-coronene, with $n=2,3$ [16].

One conspicuous feature of the ring current plots for corannulene and coronene is the complete or near absence of current density along the spoke bonds, especially in the maps showing contributions from $\pi$ electrons only $[10,17]$. Magnetically induced currents can be integrated to produce shielding tensors by means of the Biot-Savart law (as explained, for example, in [18]), and the expectation is that the low current density along the spoke bonds would translate into low levels of magnetic shielding over these bonds. However, 
the variations in off-nucleus isotropic magnetic shielding, $\sigma_{\text {iso }}(\mathbf{r})$, in various conjugated hydrocarbons (see, for example, [19-21]) suggest that the spoke bonds in both corannulene and coronene should be well-shielded; this is supported by the isotropic shielding contour plot $1 \AA$ above the molecular plane for coronene reported in [21].

The aim of this paper is to investigate aromaticity and chemical bonding in corannulene at the two stationary points on its ground-state potential energy surface, the bowlshaped local minimum of $C_{5 \mathrm{v}}$ symmetry and the planar bowl-inversion transition state of $D_{5 \mathrm{~h}}$ symmetry, by analysing, for each geometry, the changes in the off-nucleus isotropic shielding, $\sigma_{\text {iso }}(\mathbf{r})$, within the space surrounding the molecule by means of 3D isosurfaces and 2D contour plots. The $\sigma_{\text {iso }}(\mathbf{r})$ and $\sigma_{z z}(\mathbf{r})$ (the out-of-plane $z z$ component of the offnucleus shielding tensor) contour plots for $D_{5 \mathrm{~h}}$ corannulene in the molecular plane, in a plane $1 \AA$ above that plane, and the $\sigma_{\text {iso }}(\mathbf{r})$ contour plot in a vertical plane passing through the principal symmetry axis and a spoke bond are compared to the corresponding plots for coronene $\left(D_{6 \mathrm{~h}}\right.$ symmetry) in order to highlight the differences in aromaticity and bonding between the two molecules.

\section{Computational Procedure}

The gas-phase bowl-shaped $C_{5 \mathrm{v}}$ and planar $D_{5 \mathrm{~h}}$ geometries of corannulene were optimised at the B3LYP-D3(BJ)/def2-TZVP level (B3LYP with Grimme's D3 empirical dispersion corrections and Becke-Johnson damping, within the def2-TZVP basis set, as implemented in GAUSSIAN [22] which was used in all calculations reported in this paper). The gas-phase planar $D_{6 \mathrm{~h}}$ geometry of coronene, optimized at the same level of theory, was taken from [21]. These optimised geometries were confirmed as local minima $\left(C_{5 \mathrm{v}}\right.$ corannulene and $D_{6 \mathrm{~h}}$ coronene) and a transition state $\left(D_{5 \mathrm{~h}}\right.$ corannulene) through calculations of the analytical vibrational frequencies and were used in all property calculations. $\sigma_{\text {iso }}(\mathbf{r})$ isosurfaces were constructed using gas-phase B3LYP-GIAO/6-311++G(d,p) calculations (B3LYP with gauge-including atomic orbitals, within the $6-311++\mathrm{G}(\mathrm{d}, \mathrm{p})$ basis set) at regular three-dimensional grids of points with a spacing of $0.10 \AA . \sigma_{\text {iso }}(\mathbf{r})$ and $\sigma_{z z}(\mathbf{r})$ contour plots were constructed at the same level of theory but using denser regular two-dimensional grids of points with a spacing of $0.05 \AA$. To reduce computational effort, for each grid, shielding tensors were calculated at symmetry-unique points only and replicated by symmetry (using the largest Abelian subgroup of the respective point group). For visualisation purposes, all $\sigma_{\text {iso }}(\mathbf{r})$ values comprising the grid data for the bowl-shaped $C_{5 \mathrm{v}}$ and planar $D_{5 \mathrm{~h}}$ geometries of corannulene and the planar $D_{6 \mathrm{~h}}$ geometry of coronene were assembled in GAUSSIAN cube files [23]. All optimised geometries, additional computational details and the GAUSSIAN cube files with shielding data are included in the Supplementary Materials.

\section{Results}

The $C_{5 \mathrm{v}}$ geometry of corannulene and the $D_{6 \mathrm{~h}}$ geometry of coronene used throughout this paper are shown in Figure 2, which also includes details of the $D_{5 \mathrm{~h}}$ geometry of corannulene and B3LYP Mulliken charges calculated with the def2-TZVP and 6-311++G(d,p) basis sets. The experimental carbon-carbon bond lengths and corannulene bowl depth were taken from [24]; these are based on X-ray data reported in [25] and [26]. The agreement between the optimised and experimental $C_{5 \mathrm{v}}$ geometries of corannulene is very good, which is not surprising given that the more modest B3LYP/6-31G* level also produces entirely satisfactory results [25]. The slightly lower bowl depth observed at the experimental geometry is most likely due to packing effects in the crystal structure. The optimised carbon-carbon bond lengths in $D_{6 \mathrm{~h}}$ coronene closely match the experimental ones, with a slightly larger but acceptable difference for the rim bonds. The planar transition state $D_{5 \mathrm{~h}}$ geometry of corannulene features shorter hub and spoke and longer flank and rim carboncarbon bonds. The different carbon-carbon bond lengths alleviate to some extent the angle strain thought to be the main factor behind the preference for a bowl-shaped structure [2], but a significant part of this angle strain still remains. This is manifested by the inversion barrier of $\Delta G=12.3 \mathrm{kcal} / \mathrm{mol}$ obtained in the current work which compares favourably to 
the experimental estimate of $11.5 \mathrm{kcal} / \mathrm{mol}$ [27]. There are a couple of further details of the B3LYP-D3(BJ)/def2-TZVP $C_{5 \mathrm{v}}$ optimised geometry of corannulene that are worth drawing attention to: Due to the $C_{5 \mathrm{v}}$ symmetry, the carbon atoms in a six-membered rim ring lie in two planes, an "shs" plane containing the two hub and two spoke carbons and an "frf" plane containing the two flank and two rim carbons; the dihedral angle between the "shs" and "frf" planes is $169.5^{\circ}$, and as a result, the carbon periphery of the bowl is slightly tilted upwards. The rim carbons and the hydrogens connected to them lie in another plane, the angle between this plane and the "frf" plane is $174.0^{\circ}$, so the hydrogens are slightly tilted downwards, inside the bowl.

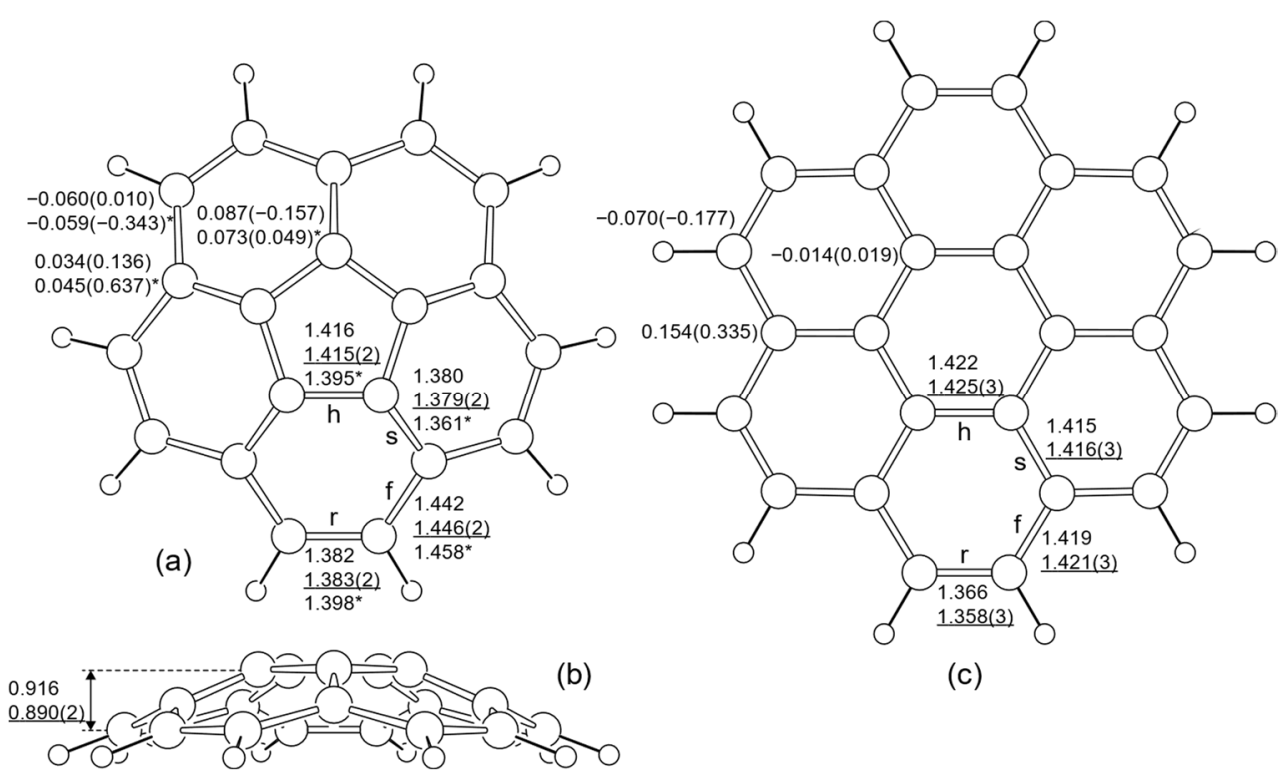

Figure 2. (a,b) $C_{5 \mathrm{v}}$ geometry of corannulene and (c) $D_{6 \mathrm{~h}}$ geometry of coronene, optimised at the B3LYP-D3(BJ)/def2-TZVP level, with bond lengths and bowl depth (in $\AA$ ) and Mulliken charges. Top bond lengths from the optimised geometries, underlined bond lengths with estimated standard deviations from X-ray data, bond lengths and Mulliken charges marked with asterisks from the $D_{5 \mathrm{~h}}$ optimised geometry of corannulene (not shown separately). B3LYP/def2-TZVP and B3LYP/6$311++G(d, p)$ Mulliken charges (in brackets). Mulliken charges for hydrogens summed into those for rim carbons. For further details, see text.

As explained in Section 1, the 6-311++G(d,p) Mulliken charges in $C_{5 \mathrm{v}}$ corannulene, -0.157 on hub carbons and 0.136 and 0.010 on flank and rim carbons, respectively, suggest a substantial rim-to-hub charge shift; this is not supported by the def2-TZVP Mulliken charges, which suggest a minor charge shift in the opposite direction. The Mulliken charges on hub carbons in the two planar geometries, $D_{5 \mathrm{~h}}$ corannulene and $D_{6 \mathrm{~h}}$ coronene, obtained with both basis sets are very low, but the two basis sets disagree considerably in the charges on the flank and rim carbons. On the whole, the large variations in Mulliken charges between the two basis sets indicate that these quantities do not provide reliable information about the charge distributions in corannulene and coronene.

The changes in isotropic shielding around $C_{5 \mathrm{v}}$ corannulene, $D_{5 \mathrm{~h}}$ corannulene and $D_{6 \mathrm{~h}}$ coronene are illustrated in Figure 3. In all three cases, the positive $\sigma_{\text {iso }}(\mathbf{r})$ isosurfaces feature conjoined shielded "doughnuts" enclosing the six-membered carbon rings, familiar from magnetic shielding studies of benzene where they were thought to demonstrate strong bonding interactions and aromatic stability $[20,28]$. The thickness of these "doughnuts" varies considerably between $C_{5 \mathrm{v}}$ corannulene, $D_{5 \mathrm{~h}}$ corannulene and $D_{6 \mathrm{~h}}$ coronene. The "doughnuts" are thickest in $D_{6 \mathrm{~h}}$ coronene and thinnest in $D_{5 \mathrm{~h}}$ corannulene, which is wellillustrated by the different sizes of the "holes" in the "doughnuts". $C_{5 \mathrm{v}}$ corannulene comes in-between, with larger "holes" outside the bowl and smaller "holes" inside the bowl. In all three cases, the most shielded bonds are the spoke bonds; the least shielded bonds 
are the hub bonds forming the inner ring; the carbon-hydrogen bonds are less shielded than those in benzene (see, for example, $[20,28]$ ), especially in $D_{6 \mathrm{~h}}$ coronene. Clearly, the switch from the $D_{5 \mathrm{~h}}$ planar geometry to the $C_{5 \mathrm{v}}$ bowl-shaped geometry of corannulene increases the shielding over all carbon-carbon bonds and enhances both bonding and the local aromaticities of the five- and six-membered rings. Thus, while the main factor behind the preference for a bowl-shaped structure is the reduction in angle strain, the shielding pictures in Figure 3 suggest non-negligible contributions from gains in bond strength and aromaticity.

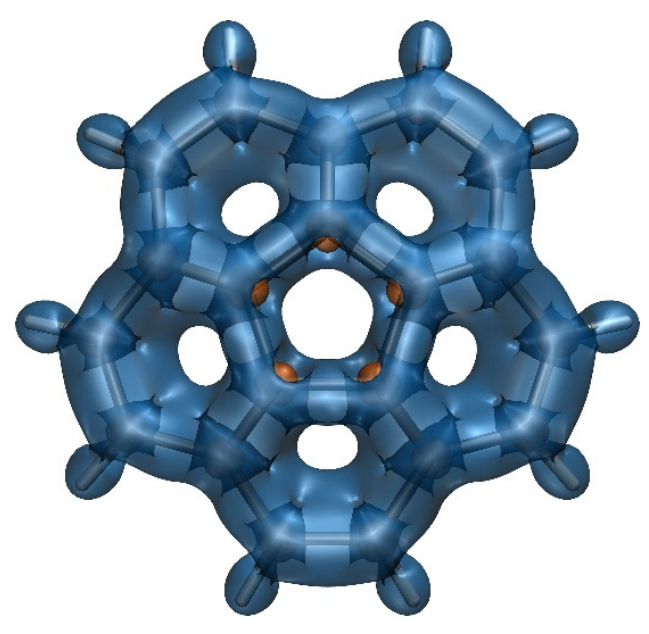

(a)

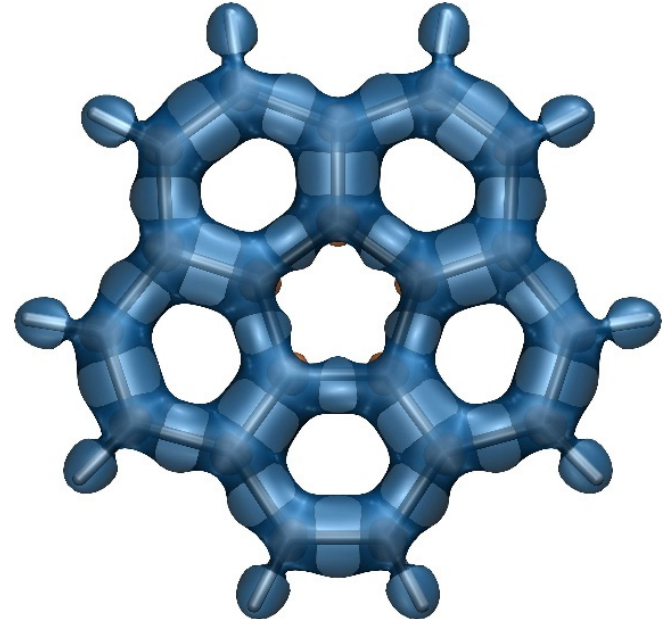

(b)

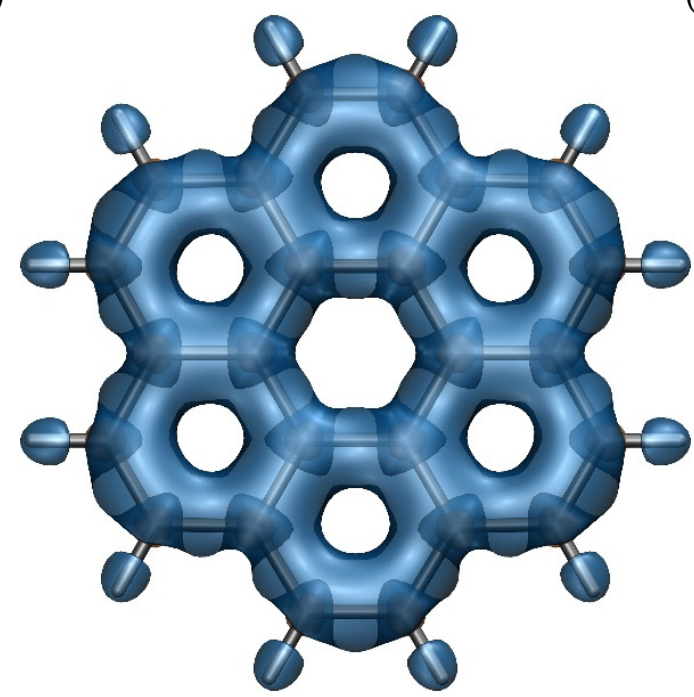

(c)

Figure 3. Top views of the isotropic shielding isosurfaces at $\sigma_{\text {iso }}(\mathbf{r})= \pm 16 \mathrm{ppm}$ for $C_{5 \mathrm{v}}$ corannulene (a), $D_{5 \mathrm{~h}}$ corannulene (b) and $D_{6 \mathrm{~h}}$ coronene (c) (positive isovalue in blue).

The carbon nuclei in corannulene and coronene are surrounded by small ovoid deshielded regions inside which $\sigma_{\text {iso }}(\mathbf{r})$ becomes negative (shown as orange isosurfaces at $-16 \mathrm{ppm}$ in Figure 3). Similar deshielded "halos" around $\mathrm{sp}^{2}$ and sp hybridised carbons and other $\mathrm{sp}^{2}$ hybridised first main row atoms have been observed previously in conjugated rings [20,28-30], as well as in open-chain conjugated molecules such as ethene, ethyne and s-trans-1,3-butadiene [19,31]. These "halos" have been attributed to a specific type of $\pi$ electron behaviour characteristic of some $\mathrm{sp}^{2}$ and $\mathrm{sp}$ hybridised first main row atoms that is different from traditional ring currents [20]. The occurrence of these "halos" in bowl-shaped corannulene confirms that the carbon atoms are close to $\mathrm{sp}^{2}$ hybridised. 
The shielding changes inside the "halos" can be seen in the $\sigma_{\text {iso }}(\mathbf{r})$ contour plots shown in Figure 4. Note that close to nuclei the isotropic shielding reverts to positive and the changes are very abrupt, as has been shown for the sp hybridised carbons in $\mathrm{C}_{2} \mathrm{H}_{2}$ [31].
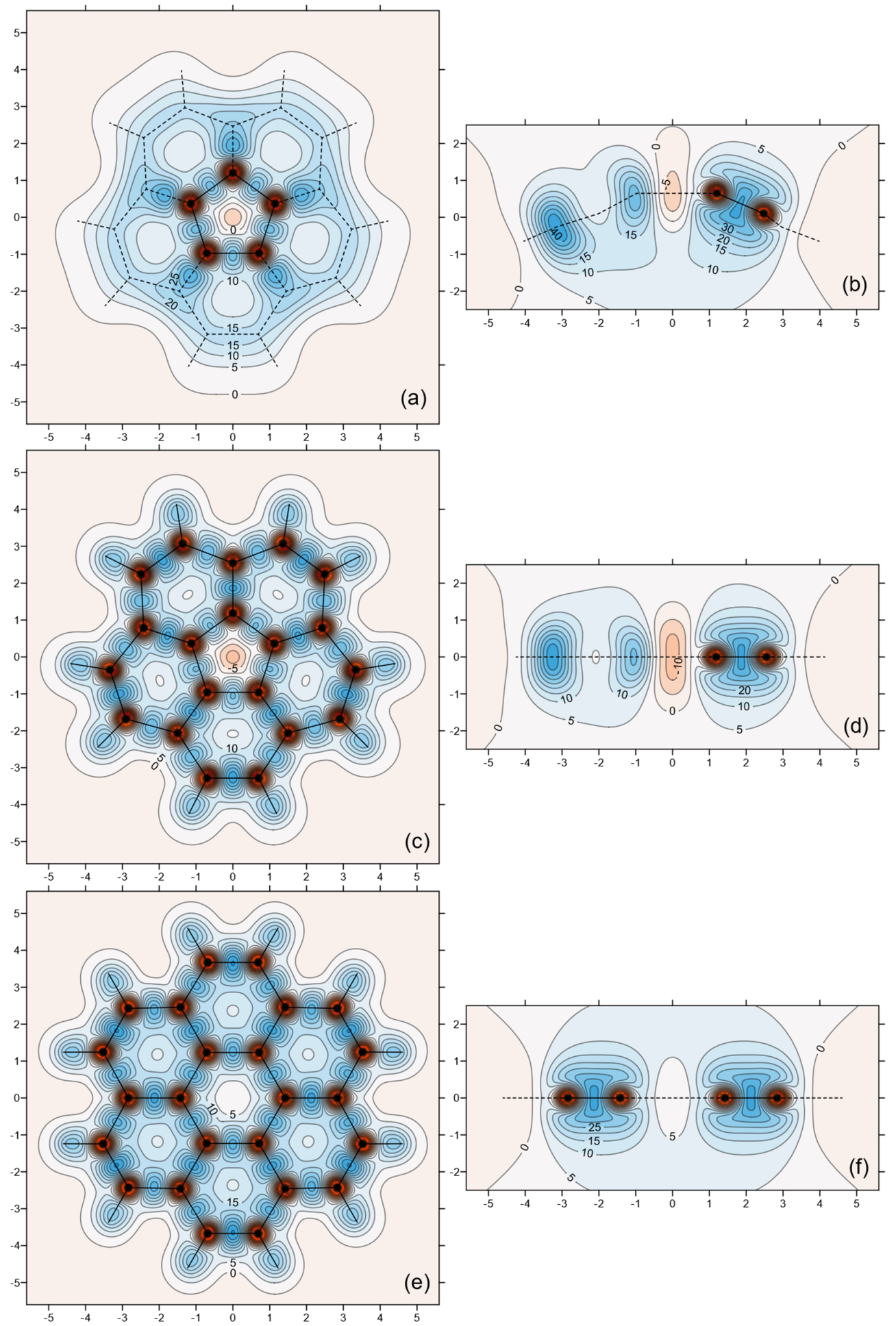

Figure 4. Isotropic shielding contour plots in the plane passing through the hub carbons (a) and a $\sigma_{\mathrm{v}}$ symmetry plane (b) for $C_{5 \mathrm{v}}$ corannulene; the molecular (horizontal) planes (c,e) and $\sigma_{\mathrm{v}}$ symmetry planes $(\mathbf{d}, \mathbf{f})$ for $D_{5 \mathrm{~h}}$ corannulene and $D_{6 \mathrm{~h}}$ coronene, respectively. Dashed lines show projections of bonds not in the plotting plane. Distances in $\AA$, contour levels at an interval of 5 ppm, red (deshielded) to blue (shielded). 
The contour plots included in Figure 4 provide more detailed information about the spatial variations in the isotropic shielding around $C_{5 \mathrm{v}}$ corannulene, $D_{5 \mathrm{~h}}$ corannulene and $D_{6 \mathrm{~h}}$ coronene. The contour plots for $C_{5 \mathrm{v}}$ and $D_{5 \mathrm{~h}}$ corannulene in Figure $4 \mathrm{a}-\mathrm{d}$ show that both geometries feature a deshielded region in the centre of the five-membered ring that extends above and below the surface of this ring. This deshielded region indicates that the hub ring in corannulene is antiaromatic, and its antiaromaticity is more pronounced in the planar $D_{5 \mathrm{~h}}$ geometry. However, the level of antiaromaticity is much lower than that in a typical antiaromatic molecule such as square cyclobutadiene $[20,28] ; \sigma_{\text {iso }}(\mathbf{r})$ does not go down to -16 ppm in the deshielded central regions, and as a result, these regions do not show in the corannulene shielding isosurfaces included in Figure 3. One consequence of the antiaromaticity of the five-membered ring is the shift in the shielding over hub bonds towards the outside of the ring, which is noticeable in Figure $3 a, b$. The low levels of shielding around the centre of the hub ring in coronene indicate that, according to the current results, this ring is between weakly aromatic and nonaromatic. Each of the contour plots in vertical symmetry planes in Figure $4 \mathrm{~b}, \mathrm{~d}, \mathrm{f}$ bisects one spoke bond; the shielding changes around each spoke bond are very similar to those around the carbon-carbon "double" bond in s-trans-1,3-butadiene (see [19]). This is an indication that the spoke bonds in corannulene and coronene have significant double bond character which, in the traditional $\sigma-\pi$ model of double bonds, requires a sizeable $\pi$ contribution. The increased levels of shielding under the bowl in $C_{5 \mathrm{v}}$ corannulene can be observed in Figure $4 \mathrm{~b}$. The contour plots in $\sigma_{\mathrm{v}}$ symmetry planes in Figure $4 \mathrm{~b}, \mathrm{~d}$ pass through the middles of a hub and a rim bond (to the left of the central ring) and provide further details about the differences between the shielding around these types of bond mentioned while discussing the features of the shielding isosurfaces in Figure $3 a, b$.

The increased shielding over the rim bonds in coronene noticeable in Figures $3 c, 4 e$ and $5 b$ (see below) supports the results of Fedik and Boldyrev [32], according to which these bonds have significant double bond character.

To gain a better understanding of the role played by the $\pi$ electrons in $D_{5 \mathrm{~h}}$ corannulene and $D_{6 \mathrm{~h}}$ coronene, we can examine the contour plots in Figure 5, which show the behaviour of $\sigma_{\text {iso }}(\mathbf{r})$ and $\sigma_{z z}(\mathbf{r})$ in planes $1 \AA$ above the respective molecular planes. These plots also facilitate comparisons to results obtained using the $\mathrm{NICS}(1)=-\sigma_{\text {iso }}$ (at $1 \AA$ above ring centre) [33] and NICS(1) $z z=-\sigma_{z z}$ (at $1 \AA$ above ring centre) [34] indices, as well as NICS-Xscan and NICS- $X Y$-scan plots [35]. Both plot types included in Figure 5 show clearly that the peripheral six-membered rings in $D_{6 \mathrm{~h}}$ coronene are more aromatic than their counterparts in $D_{5 \mathrm{~h}}$ corannulene and that the hub ring in $D_{5 \mathrm{~h}}$ corannulene is weakly antiaromatic while that in $D_{6 \mathrm{~h}}$ coronene is weakly aromatic. At first glance, the $\sigma_{z z}(\mathbf{r})$ contour plots in Figure $5 \mathrm{~b}, \mathrm{~d}$ look like accentuated versions of the respective $\sigma_{\text {iso }}(\mathbf{r})$ contour plots in Figure 5a,c; however, careful examination reveals some interesting and important differences. The regions of large positive $\sigma_{z z}(\mathbf{r})$ values along (and mainly on the inside of) the peripheries of $D_{5 \mathrm{~h}}$ corannulene and $D_{6 \mathrm{~h}}$ coronene can be associated with the diamagnetic peripheral $\pi$ currents, stronger in corannulene and weaker in coronene, observed by Jenneskens and coworkers [10]. According to these authors, there should be strong and weak paramagnetic hub $\pi$ currents along the hub rings of $D_{5 \mathrm{~h}}$ corannulene and $D_{6 \mathrm{~h}}$ coronene, respectively. The negative $\sigma_{z z}(\mathbf{r})$ values inside the hub ring of $D_{5 \mathrm{~h}}$ corannulene can be thought to arise due to paramagnetic hub $\pi$ currents, but the positive $\sigma_{z z}(\mathbf{r})$ values inside the hub ring of $D_{6 \mathrm{~h}}$ coronene cannot be interpreted in this way. While present in the $\sigma_{\text {iso }}(\mathbf{r})$ plots, these details are easier to discern in the $\sigma_{z z}(\mathbf{r})$ plots, especially in that for $D_{5 \mathrm{~h}}$ corannulene.

The ring current plots in the literature [10,36-38] do not include features that correspond to the sizeable regions of negative $\sigma_{z z}(\mathbf{r})$ values observed just outside the peripheral carbon rings in $D_{5 \mathrm{~h}}$ corannulene and $D_{6 \mathrm{~h}}$ coronene (see Figure $5 \mathrm{c}, \mathrm{d}$ ). There are no deshielded regions at these locations in the $\sigma_{\text {iso }}(\mathbf{r})$ contour plots in Figure $5 \mathrm{a}, \mathrm{b}$, but both molecules are surrounded by slightly deshielded areas. 

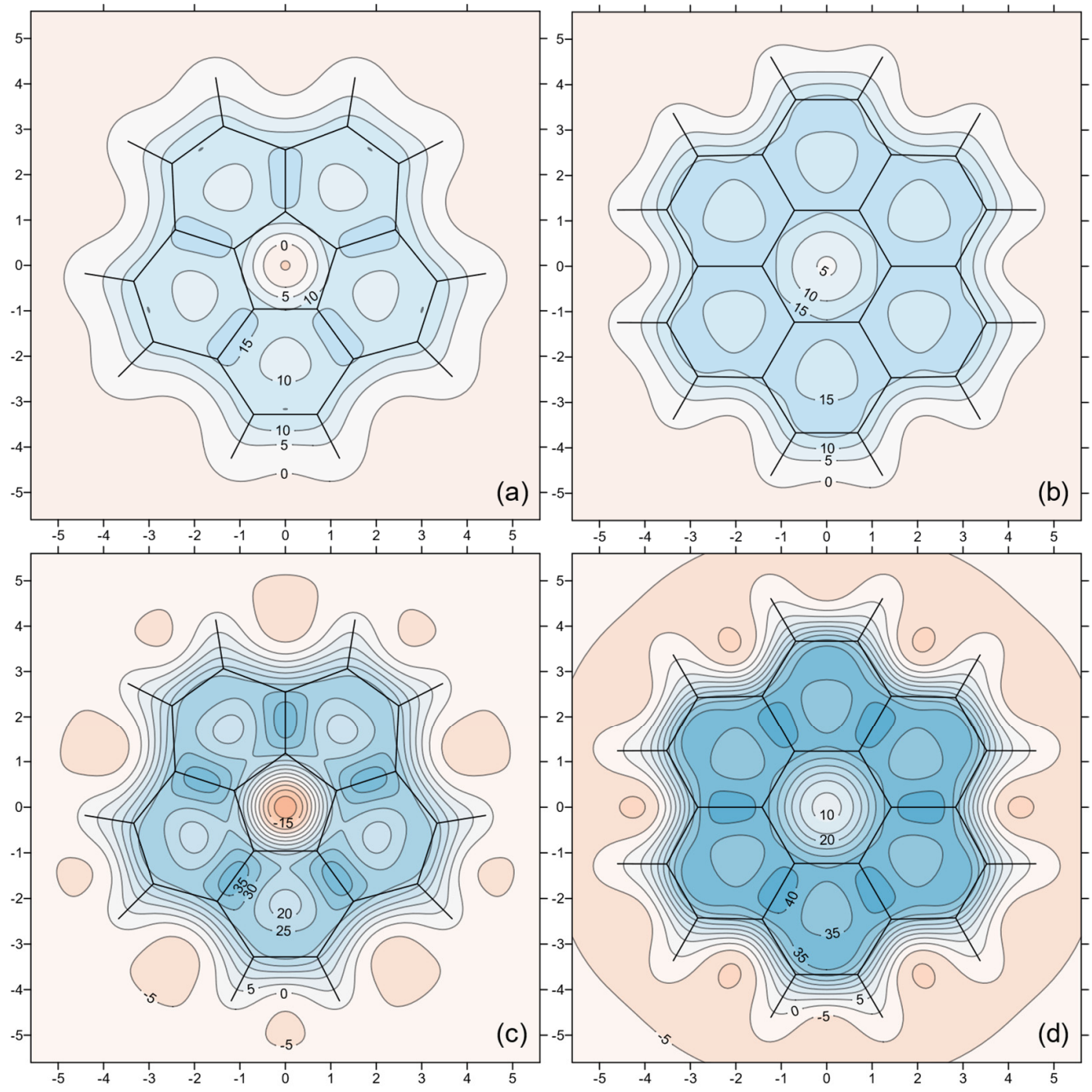

Figure 5. $\sigma_{\text {iso }}(\mathbf{r})(\mathbf{a}, \mathbf{b})$ and $\sigma_{z z}(\mathbf{r})(\mathbf{c}, \mathbf{d})$ contour plots for $D_{5 \mathrm{~h}}$ corannulene $(\mathbf{a}, \mathbf{c})$ and $D_{6 \mathrm{~h}}$ coronene $(\mathbf{b}, \mathbf{d})$ in planes $1 \AA$ above the respective molecular planes, details as for Figure 4 .

A more noticeable discrepancy between the $\sigma_{z z}(\mathbf{r})$ contour plots for $D_{5 \mathrm{~h}}$ corannulene and $D_{6 \mathrm{~h}}$ coronene in Figure $5 \mathrm{c}, \mathrm{d}$ and ring current studies is associated with the regions of increased $\sigma_{z z}(\mathbf{r})$ values, above $35 \mathrm{ppm}$ in Figure $5 \mathrm{c}$ and above $40 \mathrm{ppm}$ in Figure $5 \mathrm{~d}$, over carbon-carbon spoke bonds-as a result, one would expect to see strong currents over these bonds, but ring current plots indicate that there are next to no currents over spoke bonds. The absence of currents over spoke bonds has been attributed to the combination of diamagnetic local ring currents in all six-membered rings [39], but this explanation does not account for the increased shielding of the spoke bonds.

As demonstrated by the plots in Figure 5c,d and the work of other authors [40-42], $\sigma_{z z}(\mathbf{r})$ and related plots offer a viable alternative to their $\sigma_{\text {iso }}(\mathbf{r})$ counterparts when studying planar conjugated molecules. While we can choose between $\sigma_{\text {iso }}(\mathbf{r})$ and $\sigma_{z z}(\mathbf{r})$ contour plots when describing planar molecules, for nonplanar molecules such as $C_{5 \mathrm{v}}$ corannulene we would need to use $\sigma_{\text {iso }}(\mathbf{r})$ isosurfaces and/or contour plots cutting through these isosurfaces.

The isotropic shieldings for all nuclei in $C_{5 \mathrm{v}}$ corannulene, $D_{5 \mathrm{~h}}$ corannulene and $D_{6 \mathrm{~h}}$ coronene are shown in Table 1, together with the NICS(0) and NICS(1) or NICS $( \pm 1)$ values for all five- and six-membered rings. The use of NICS $( \pm 1)$ for $C_{5 \mathrm{v}}$ corannulene is necessitated by the fact that it is nonplanar and the shielding environments outside and inside the bowl, influencing the NICS(+1) and NICS(-1) values, respectively, are different. Calculating NICS $( \pm 1)$ for the hub ring in $C_{5 \mathrm{v}}$ corannulene is not a problem because the 
ring is planar and it is straightforward to locate points $1 \AA$ above and below the ring centre, along the $C_{5}$ axis. The nonplanar six-membered rim rings require a different approach: a plane is fitted to the coordinates of the ring atoms and ring centre and $\operatorname{NICS}( \pm 1)$ values are calculated at the points $1 \AA$ above and below that plane along the normal passing through the ring centre following the procedure outlined in $[43,44]$.

Table 1. Isotropic shieldings for all nuclei in $C_{5 \mathrm{v}}$ corannulene, $D_{5 \mathrm{~h}}$ corannulene and $D_{6 \mathrm{~h}}$ coronene, as well as NICS(0) and NICS $(1)$ or NICS $( \pm 1)$ values (in ppm) for the hub (central) and rim (peripheral) rings, calculated at the B3LYP-GIAO/6-311++G(d,p)//B3LYP-D3(BJ)/def2-TZVP level. The NICS(1) values for the two planar geometries are shown in the respective NICS $(+1)_{\text {hub }}$ and NICS $(+1)_{\text {rim }}$ rows.

\begin{tabular}{cccc}
\hline Property & $\boldsymbol{C}_{\mathbf{5 v}}$ Corannulene & $\boldsymbol{D}_{\mathbf{5 h}}$ Corannulene & $\boldsymbol{D}_{\mathbf{6 h}}$ Coronene \\
\hline$\sigma_{\text {iso }}\left(\mathrm{C}_{\text {hub }}\right)$ & 41.6 & 47.1 & 57.0 \\
$\sigma_{\text {iso }}\left(\mathrm{C}_{\text {flank }}\right)$ & 46.8 & 51.4 & 50.1 \\
$\sigma_{\text {iso }}\left(\mathrm{C}_{\text {rim }}\right)$ & 51.4 & 50.2 & 52.9 \\
$\sigma_{\text {iso }}(\mathrm{H})$ & 24.0 & 23.9 & 22.7 \\
NICS $(0)_{\text {hub }}$ & 8.2 & 11.9 & -0.1 \\
NICS $(+1)_{\text {hub }}$ & 2.9 & 5.3 & -4.6 \\
NICS $(-1)_{\text {hub }}$ & -4.2 & & -9.7 \\
NICS $(0)_{\text {rim }}$ & -6.5 & -4.7 & -12.0 \\
NICS $(+1)_{\text {rim }}$ & -5.4 & -7.5 & \\
NICS $(-1)_{\text {rim }}$ & -13.0 & & \\
\hline
\end{tabular}

The NICS $(0)$ and NICS(1) or NICS $( \pm 1)$ values reported in Table 1 confirm the conclusions about the local aromaticities of the five- and six-membered rings of carbon atoms in $C_{5 \mathrm{v}}$ corannulene, $D_{5 \mathrm{~h}}$ corannulene and $D_{6 \mathrm{~h}}$ coronene made by examining the $\sigma_{\text {iso }}(\mathbf{r})$ isosurfaces and $\sigma_{\text {iso }}(\mathbf{r})$ and $\sigma_{z z}(\mathbf{r})$ contour plots in Figures 3-5: the five-membered hub ring in both the bowl-shaped and planar geometries of corannulene is antiaromatic, more so in the planar geometry; the six-membered hub ring in coronene comes out as weakly aromatic; all six-membered rim rings are aromatic, with their aromaticities increasing in the order $D_{5 \mathrm{~h}}$ corannulene $<C_{5 \mathrm{v}}$ corannulene $<D_{6 \mathrm{~h}}$ coronene.

While the accurate reproduction of the experimentally measured chemical shifts in corannulene and coronene is not amongst the aims of this paper, it is interesting to examine the extent to which the gas-phase B3LYP-GIAO/6-311++G(d,p)//B3LYP-D3(BJ)/def2TZVP carbon isotropic shieldings agree with experimental data and other theoretical estimates. As shown in Table 2, the differences between the isotropic shieldings for the hub, flank and rim carbons in $C_{5 \mathrm{v}}$ corannulene and $D_{6 \mathrm{~h}}$ coronene obtained in this work are reasonably close to the differences between the respective liquid-state NMR chemical shifts and are more accurate than the CTOCD-PZ2 differences from HF-level calculations with a smaller basis set [10].

Table 2. Differences between ${ }^{13} \mathrm{C}$ chemical shifts $(\delta)$ from the literature and the isotropic shieldings obtained in this work for $C_{5 \mathrm{v}}$ corannulene and $D_{6 \mathrm{~h}}$ coronene (in ppm).

\begin{tabular}{|c|c|c|}
\hline Property & $C_{5 \mathrm{v}}$ Corannulene & $D_{6 \mathrm{~h}}$ Coronene \\
\hline$\delta\left(\mathrm{C}_{\mathrm{hub}}\right) \delta\left(\mathrm{C}_{\text {flank }}\right)$ & $5.0^{\mathrm{a}}, 6.4^{\mathrm{b}}$ & $-6.1^{a},-4.7^{b}$ \\
\hline$\sigma_{\text {iso }}\left(\mathrm{C}_{\text {flank }}\right) \sigma_{\text {iso }}\left(\mathrm{C}_{\text {hub }}\right)$ & 5.2 & -6.9 \\
\hline$\delta\left(\mathrm{C}_{\text {hub }}\right) \delta\left(\mathrm{C}_{\text {rim }}\right)$ & $8.6^{\mathrm{a}}, 10.7^{\mathrm{b}}$ & $-3.6^{\mathrm{a}},-2.2^{\mathrm{b}}$ \\
\hline$\sigma_{\text {iso }}\left(\mathrm{C}_{\text {rim }}\right) \sigma_{\text {iso }}\left(\mathrm{C}_{\text {hub }}\right)$ & 9.8 & -4.1 \\
\hline
\end{tabular}

a From experimental ${ }^{13} \mathrm{C}$ chemical shifts for $C_{5 \mathrm{v}}$ corannulene and $D_{6 \mathrm{~h}}$ coronene measured in $\mathrm{CDCl}_{3}$, taken from [45] and [10], respectively. ${ }^{\mathrm{b}}$ From ${ }^{13} \mathrm{C}$ chemical shifts for $C_{5 \mathrm{v}}$ corannulene and $D_{6 \mathrm{~h}}$ coronene calculated using CTOCD-PZ2 (the parametric zero variant of the continuous transformation of origin of current density) method [46] with Hartree-Fock (HF) HF/6-31++G wavefunctions at HF/6-31++G optimised geometries [10]. 


\section{Conclusions}

The investigation of aromaticity and chemical bonding in the bowl-shaped $C_{5 \mathrm{v}}$ and planar $D_{5 \mathrm{~h}}$ geometries of corannulene and the planar $D_{6 \mathrm{~h}}$ geometry of coronene through a visual approach based on the analysis of 3D isotropic magnetic shielding isosurfaces and 2D contour plots of the isotropic magnetic shielding and, for planar geometries, of the out-of-plane principal component of the off-nucleus shielding tensor provides insights and levels of detail that would be difficult to obtain using other theoretical approaches.

A common feature of corannulene at its $C_{5 \mathrm{v}}$ and $D_{5 \mathrm{~h}}$ geometries and $D_{6 \mathrm{~h}}$ coronene is the presence of conjoined shielded "doughnuts" enclosing the peripheral six-membered carbon rings and suggesting strong bonding interactions and aromatic stability. The thickest "doughnuts" are observed in $D_{6 \mathrm{~h}}$ coronene, and the thinnest "doughnuts" are observed in $D_{5 \mathrm{~h}}$ corannulene; $C_{5 \mathrm{v}}$ corannulene comes in-between, with larger "holes" towards the less shielded exterior of the bowl and smaller "holes" towards the more shielded interior of the bowl. The deshielded region within the hub ring in corannulene indicates that this ring is antiaromatic, more so in the planar $D_{5 \mathrm{~h}}$ geometry. We observe that the switch from the $D_{5 \mathrm{~h}}$ planar geometry to the $C_{5 \mathrm{v}}$ bowl-shaped geometry of corannulene increases the shielding over all carbon-carbon bonds and enhances both bonding and the local aromaticities of the five- and six-membered rings; in addition to angle-strain reduction, these gains in bond strength and aromaticity favour the bowl-shaped geometry. In both corannulene and coronene, the most shielded bonds turn out to be the spoke bonds, with levels of shielding very similar to those around the carbon-carbon "double" bond in s-trans-1,3-butadiene [19]; the least shielded bonds are the bonds forming the hub ring. The higher $\pi$ electron activity over spoke bonds in planar corannulene and coronene is supported by contour plots of the out-of-plane principal component of the off-nucleus shielding tensor in planes $1 \AA$ above the respective molecular planes; these findings about spoke bonds are somewhat unexpected, given that ring current studies indicate next to no currents over spoke bonds (see, for example, [10]).

The small deshielded "halos" surrounding carbon atoms in bowl-shaped corannulene confirm that these carbon atoms are close to $\mathrm{sp}^{2}$ hybridised; this feature, as well as the increased shielding on the inside of the bowl, should be present in the isotropic magnetic shielding pictures for buckminsterfullerene and other fullerenes.

Supplementary Materials: The following are available online at https:/ / www.mdpi.com/article / $10.3390 /$ chemistry3030063/s1, ZIP archive containing the $\sigma_{\text {iso }}(\mathbf{r})$ GAUSSIAN cube files for $C_{5 \mathrm{v}}$ corannulene, $D_{5 \mathrm{~h}}$ corannulene and $D_{6 \mathrm{~h}}$ coronene; a Word file with additional computational details and all optimized geometries.

Institutional Review Board Statement: Not applicable.

Informed Consent Statement: Not applicable.

Data Availability Statement: Not applicable.

Conflicts of Interest: The author declares no conflict of interest.

\section{References}

1. Barth, W.E.; Lawton, R.G. Dibenzo[ghi,mno]fluoranthene. J. Am. Chem. Soc. 1966, 88, 380-381. [CrossRef]

2. Lawton, R.G.; Barth, W.E. The synthesis of corannulene. J. Am. Chem. Soc. 1971, 93, 1730-1745. [CrossRef]

3. Kroto, H.W.; Heath, J.R.; O’Brien, S.C.; Curl, R.F.; Smalley, R.E. C 60 : Buckminsterfullerene. Nature 1985, 318, 162-163. [CrossRef]

4. Stuparu, M.C. Corannulene: A curved polyarene building block for the construction of functional materials. Acc. Chem. Res. 2021, 54, 2858-2870. [CrossRef]

5. Butterfield, A.M.; Gilomen, B.; Siegel, J.S. Kilogram-scale production of corannulene. Org. Process Res. Dev. 2012, 16, 664-676. [CrossRef]

6. Monaco, G.; Scott, L.T.; Zanasi, R. Magnetic euripi in corannulene. J. Phys. Chem. A 2008, 112, 8136-8147. [CrossRef] [PubMed]

7. Dunning, T.H., Jr.; Xu, L.T.; Cooper, D.L.; Karadakov, P.B. Spin-coupled generalized valence bond theory: New perspectives on the electronic structure of molecules and chemical bonds. J. Phys. Chem. A 2021, 125, 2021-2050. [CrossRef] [PubMed]

8. Sironi, M.; Cooper, D.L.; Gerratt, J.; Raimondi, M. The modern valence bond description of naphthalene. J. Chem. Soc. Chem. Commun. 1989, 675-677. [CrossRef] 
9. Sygula, A.; Rabideau, P.W. Structure and inversion barriers of corannulene, its dianion and tetraanion. An ab initio study. J. Mol. Struc. THEOCHEM 1995, 333, 215-226. [CrossRef]

10. Steiner, E.; Fowler, P.W.; Jenneskens, L.W. Counter-rotating ring currents in coronene and corannulene. Angew. Chem. Int. Ed. 2001, 40, 362-366. [CrossRef]

11. Bühl, M. The relation between endohedral chemical shifts and local aromaticities in fullerenes. Chem. Eur. J. 1998, 4, 734-739. [CrossRef]

12. Li, J.; Rogachev, A.Y. Aromatic stabilization of functionalized corannulene cations. Phys. Chem. Chem. Phys. 2016, 18, 11781-11791. [CrossRef]

13. Schleyer, P.v.R.; Maerker, C.; Dransfeld, A.; Jiao, H.; van Eikema Hommes, N.J.R. Nucleus-independent chemical shifts: A simple and efficient aromaticity probe. J. Am. Chem. Soc. 1996, 118, 6317-6318. [CrossRef] [PubMed]

14. Monaco, G.; Zanasi, R. Three contra-rotating currents from a rational design of polycyclic aromatic hydrocarbons: Altancorannulene and altan-coronene. J. Phys. Chem. A 2012, 116, 9020-9026. [CrossRef]

15. Monaco, G.; Zanasi, R. Anionic Derivatives of Altan-Corannulene. J. Phys. Org. Chem. 2013, 26, 730-736. [CrossRef]

16. Dickens, T.K.; Mallion, R.B. Topological ring-currents and bond-currents in hexaanionic altans and iterated altans of corannulene and coronene. J. Phys. Chem. A 2020, 124, 7973-7990. [CrossRef]

17. Kaipio, M.; Patzschke, M.; Fliegl, H.; Pichierri, F.; Sundholm, D. Effect of fluorine substitution on the aromaticity of polycyclic hydrocarbons. J. Phys. Chem. A 2012, 116, 10257-10268. [CrossRef]

18. Pelloni, S.; Ligabue, A.; Lazzeretti, P. Ring-current models from the differential Biot-Savart law. Org. Lett. 2004, 6, 4451-4454. [CrossRef]

19. Karadakov, P.B.; Horner, K.E. Exploring chemical bonds through variations in magnetic shielding. J. Chem. Theory Comput. 2016, 12, 558-563. [CrossRef]

20. Karadakov, P.B.; Hearnshaw, P.; Horner, K.E. Magnetic shielding, aromaticity, antiaromaticity, and bonding in the low-lying electronic states of benzene and cyclobutadiene. J. Org. Chem. 2016, 81, 11346-11352. [CrossRef]

21. Lampkin, B.J.; Karadakov, P.B.; VanVeller, B. Detailed visualization of aromaticity using isotropic magnetic shielding. Angezw. Chem. Int. Ed. 2020, 59, 19275-19281. [CrossRef]

22. Frisch, M.J.; Trucks, G.W.; Schlegel, H.B.; Scuseria, G.E.; Robb, M.A.; Cheeseman, J.R.; Scalmani, G.; Barone, V.; Petersson, G.A.; Nakatsuji, H.; et al. Gaussian 16, Revision A.03; Gaussian, Inc.: Wallingford, CT, USA, 2016.

23. Cubegen. Available online: https://gaussian.com/cubegen/ (accessed on 30 July 2021).

24. Filatov, A.S.; Sumner, N.J.; Spisak, S.N.; Zabula, A.V.; Petrukhina, M.A. Jahn-Teller effect in circulenes: X-ray diffraction study of coronene and corannulene radical anions. Chem. Eur. J. 2012, 18, 15753-15760. [CrossRef]

25. Petrukhina, M.A.; Andreini, K.W.; Mack, J.; Scott, L.T. X-ray quality geometries of geodesic polyarenes from theoretical calculations: What levels of theory are reliable? J. Org. Chem. 2005, 70, 5713-5716. [CrossRef]

26. Krygowski, T.M.; Cyrański, M.; Ciesielski, A.; Swirska, B.; Leszczyński, P. Separation of the energetic and geometric contributions to aromaticity. 2. Analysis of the aromatic character of benzene rings in their various topological environments in the benzenoid hydrocarbons. Crystal and molecular structure of coronene. J. Chem. Inf. Comput. Sci. 1996, 36, 1135-1141. [CrossRef]

27. Seiders, T.J.; Baldridge, K.K.; Grube, G.H.; Siegel, J.S. Structure/energy correlation of bowl depth and inversion barrier in corannulene derivatives: Combined experimental and quantum mechanical analysis. J. Am. Chem. Soc. 2001, 123, 517-525. [CrossRef] [PubMed]

28. Karadakov, P.B.; Horner, K.E. Magnetic shielding in and around benzene and cyclobutadiene: A source of information about aromaticity, antiaromaticity and chemical bonding. J. Phys. Chem. A 2013, 117, 518-523. [CrossRef]

29. Horner, K.E.; Karadakov, P.B. Chemical bonding and aromaticity in furan, pyrrole and thiophene: A magnetic shielding study. J. Org. Chem. 2013, 78, 8037-8043. [CrossRef]

30. Horner, K.E.; Karadakov, P.B. Magnetic shielding in and around oxazole, imidazole and thiazole: How does the second heteroatom affect aromaticity and bonding? J. Org. Chem. 2015, 80, 7150-7157. [CrossRef]

31. Karadakov, P.B.; Kirsopp, J. Magnetic shielding studies of $\mathrm{C}_{2}$ and $\mathrm{C}_{2} \mathrm{H}_{2}$ support higher than triple bond multiplicity in $\mathrm{C}_{2}$. Chem. Eur. J. 2017, 23, 12949-12954. [CrossRef] [PubMed]

32. Fedik, N.; Boldyrev, A.I. Insight into the nature of rim bonds in coronene. J. Phys. Chem. A 2013, 117, 8585-8590. [CrossRef]

33. Schleyer, P.R.; Manoharan, M.; Wang, Z.X.; Kiran, B.; Jiao, H.; Puchta, R.; van Eikema Hommes, N.J.R. Dissected nucleusindependent chemical shift analysis of $\pi$-aromaticity and antiaromaticity. Org. Lett. 2001, 3, 2465-2468. [CrossRef]

34. Fallah-Bagher-Shaidaei, H.; Wannere, C.S.; Corminboeuf, C.; Puchta, R.; Schleyer, P.v.R. Which NICS aromaticity index for planar $\pi$ rings is best? Org. Lett. 2006, 8, 863-866. [CrossRef]

35. Gershoni-Poranne, R.; Stanger, A. The NICS-XY-scan: Identification of local and global ring currents in multi-ring systems. Chem. Eur. J. 2014, 20, 5673-5688. [CrossRef] [PubMed]

36. Fias, S.; Fowler, P.W.; Delgado, J.L.; Hahn, U.; Bultinck, P. Correlation of delocalization indices and current-density maps in polycyclic aromatic hydrocarbons. Chem. Eur. J. 2008, 14, 3093-3099. [CrossRef]

37. Fliegl, H.; Taubert, S.; Lehtonen, O.; Sundholm, D. The gauge including magnetically induced current method. Phys. Chem. Chem. Phys. 2011, 13, 20500-20518. [CrossRef] [PubMed]

38. Geuenich, D.; Hess, K.; Köhler, F.; Herges, R. Anisotropy of the induced current density (ACID), a general method to quantify and visualize electronic delocalization. Chem. Rev. 2005, 105, 3758-3772. [CrossRef] 
39. Kumar, A.; Duran, M.; Solà, M. Is coronene better described by Clar's aromatic $\pi$-sextet model or by the AdNDP representation? J. Comput. Chem. 2017, 38, 1606-1611. [CrossRef]

40. Merino, G.; Heine, T.; Seifert, G. The induced magnetic field in cyclic molecules. Chem. Eur. J. 2004, 10, 4367-4371. [CrossRef]

41. Heine, T.; Corminboeuf, C.; Seifert, G. The magnetic shielding function of molecules and pi-electron delocalization. Chem. Rev. 2005, 105, 3889-3910. [CrossRef]

42. Heine, T.; Islas, R.; Merino, G. $\sigma$ and $\pi$ contributions to the induced magnetic field: Indicators for the mobility of electrons in molecules. J. Comput. Chem. 2007, 28, 302-309. [CrossRef]

43. Matito, E.; Poater, J.; Duran, M.; Solà, M. An analysis of the changes in aromaticity and planarity along the reaction path of the simplest diels-alder reaction. Exploring the validity of different indicators of aromaticity. J. Mol. Struct. THEOCHEM 2005, 727, 165-171. [CrossRef]

44. Dobrowolski, J.C.; Lipiński, P.F.J. On splitting of the NICS(1) magnetic aromaticity index. RSC Adv. 2016, 6, 23900-23904. [CrossRef]

45. Scott, L.T.; Cheng, P.-C.; Hashemi, M.M.; Bratcher, M.S.; Meyer, D.T.; Warren, H.B. Corannulene. A three-step synthesis. J. Am. Chem. Soc. 1997, 119, 10963-10968. [CrossRef]

46. Zanasi, R.; Lazzeretti, P.; Malagoli, M.; Piccinini, F. Molecular magnetic properties within continuous transformations of origin of the current density. J. Chem. Phys. 1995, 102, 7150-7157. [CrossRef] 